\title{
PENERAPAN CORPORATE SOCIAL RESPONSIBILITY PADA BCA DAN BMI PERSPEKTIF EKONOMI ISLAM
}

\author{
ULUL AZMI MUSTOFA \\ STIE AAS Surakarta \\ ululazmimsi@gmail.com
}

\begin{abstract}
The purpose of the thesis is to acknowledge the application of CSR in BCA Bank and BMI Bank period 2012, and what resources of fund are using in CSR programs, and to see Islamic economic about application CSR Bank BCA and Bank Muamamalat. This research is a qualitative research and research type is comparative research. The analyze that used are reduction method, data presentation and conclusion.

This thesis concludes that the implementation of CSR in Bank BCA and Bank Muamalat there is a change for the better from years to years. The application of CSR from philantropic to strategic. And than, resources of fund are using in CSR programs there is some resources, Bank BCA there is two resources. In other hand, Bank Muamalat there is some resources funds for implemetation of CSR. And than, In Perspective Islamic Economic, Islam Position in CSR Continuum, Implementation of CSR in Bank BCA is Strategic, and than implementation of CSR in Bank BMI is Taqwa-Centric.
\end{abstract}

Key words: implementation, Corporate Social Responsibility, Islamic Economic

\section{PENDAHULUAN}

\section{A. Latar Belakang}

Pada awalnya pelaksanaan CSR hanya bersifat sukarela (voluntary). Hal ini sejalan dengan pendapat Isa Wahyudi, bahwa meskipun belum ada kesatuan bahasa dalam memaknai CSR, tetapi CSR ini telah diimplimentasikan oleh perusahaan dalam berbagai bentuk kegiatan yang didasarkan atas kesukarelaan. ${ }^{1}$ Hal inilah yang menjadi masalah karena sifat kesukarelaan ini menjadi peluang perusahaan untuk tidak melaksanakan CSR. Hal itulah yang dikhawatirkan jika tidak ada peraturan yang bersifat mengikat pada perusahaan untuk menjalankan CSR.

\footnotetext{
${ }^{1}$ Isa Wahyudi \& Busyra Azheri. Corporate Social Responsibility: Prinsip, Pengaturan dan Implementasi, (Malang: In-Trans Publishing, 2008), hal. xv.
} 
Tetapi,

pada

perkembangannya CSR menjadi sangat popluler, karena CSR menjadi salah satu pengukur untuk menilai keberhasilan perusahaan dalam operasionalnya di berbagai belahan dunia. ${ }^{2}$ Sehingga CSR dinilai wajib untuk diterapkan perusahaan. Kewajiban ini juga ditopang oleh kebijakan pemerintah untuk mewajibkan perusahaan dalam kegiatan sosial dilingkungannya.

Penerapan CSR di perusahaan didasarkan pada beberapa faktor, yaitu pertama, adanya undangundang yang mewajibkan perusahaan untuk menjalankan CSR. $^{3}$ Adanya ketetapan untuk melakukan kegiatan yang harus berdasarkan pada tanggung jawab sosial dan lingkungan baik berupa undang-undang maupun peraturan pemerintah seperti, Undang Undang No 40 tahun 2007 pasal 74 tentang kewajiban Perseroan, undangundang No. 25 tahun 2007 tentang Penanaman Modal, dan peraturan yang terbaru berupa peraturan pemerintah No. 47 tahun 2012 tentang tanggung jawab sosial dan lingkungan perseroan terbatas dan lain sebagainya. Adanya Undangundang tersebut mewajibkan perusahaan-perusahaan

di

2 Muhammad Yasir Yusuf, "Model Pelaksanaan CSR Bank Syariah: Kajian Empiris Pembiayaan Mikro Baitul Mal Aceh", Jurnal La-riba Volume IV. No. 2 (Desember 2010), hal.198

Lihat Undang-Undang No 40 tahun 2007 pasal 74 tentang Perseroan terbatas.
Indonesia menjalankan program CSR tidak terkecuali perusahaan jasa, dalam hal ini adalah perusahaan perbankan. Apabila perusahaan tidak melaksanakan program CSR maka pemerintah dapat memberikan sanksi sesuai dengan ketentuan undang-undang yang berlaku. Sanksi ini didasarkan pada UU No 40 tahun 2007 pasal 74 ayat 3 tentang pelaksanaan CSR. Adanya undang-undang ini menjadi salah satu pemicu motivasi perusahaan untuk menjalankan CSR.

Selain itu pula, dasar pelaksanaan CSR adalah adanya nafas etika bisnis dalam sebuah perusahaan perseroan, meskipun secara samar namun melekat. ${ }^{4} \mathrm{Hal}$ ini juga tercantum pada penjelasan Undang Undang Perseroan Terbatas. $^{5}$ Dalam artian bahwa perseroan seharusnya memiliki suatu hubungan yang harmonis, serasi dan seimbang sesuai dengan nilai, moral, dan budaya masyarakat setempat. Hal ini menunjukkan bahwa perseroan dibatasi, dalam artian perusahaan haruslah menjaga nilai-nilai etis dengan masyarakat secara baik selain konsentrasi pada aspek dunia bisnis.

Konsep CSR bertujuan untuk mejadikan kegiatan bisnis yang

4 T. Gayus Lumbun. Telaah Hukum Atas Ketentuan Corporate Social Responsbility dalam UUPT (undang-undang Perseroan Terbatas). Makalah, hal.2. 198. 
bersinergi positif dengan kegiatan masyarakat sehingga tidak ada yang dirugikan dari adanya sebuah perusahaan. Sehingga harus ada kesadaran pada pelaksanaan CSR menjadi tanggung jawab bersama untuk menciptakan keharmonisan dan keselarasan antar stakeholder. ${ }^{6}$

Pelaksanaan CSR di Indonesia secara umum lebih banyak diterapkan oleh perusahaan tambang atau manufaktur. Tetapi pada perkembangannya, seiring dengan adanya tren global pelaksanaan CSR, saat ini perusahaan di bidang jasa seperti perbankan juga telah menyajikan aspek tanggung jawab sosial dalam laporan tahunan. Hal ini dilakukan tidak hanya oleh bank konvensional tetapi juga dilakukan oleh bank syariah.

Tetapi pada kenyataannya, perusahaan perbankan pada saat ini hanya menjadikan CSR sebagai tren untuk menggaet nasabah, yaitu dengan memberikan pencitraan yang baik semata. Seharusnya yang dilakukan perusahaan perbankan adalah menghapus berbagai anggapan bahwa CSR sebagai pengelabuhan citra (green wash) karena tidak memperhatikan dampak bisnis inti namun

${ }^{6}$ Muhammad Yasir Yusuf dan Zakaria Bin Bahari, Islamic Corporate Social Responsbility in Islamic Banking: Towards Poverty Alleviation, Makalah di seminarkan pada $8^{\text {th }}$ International Conference on Islamic Economics and finance, Center for Islamic and Finance, Qatar Faculty of Islamic Studies, Qatar Fondation, Qatar, hal. 2. mengalihkan ke hal-hal lain dan alat promosi.

Oleh karena itu, perlu dibuktikan apakah pelaksanaan CSR pada bank konvensional sebenarnya sama dengan pelaksanaan CSR bank Syariah. Ataukah pelaksanaan bank konvensional dan bank syariah sama saja, hanya bermotifkan untuk memoles image semata tanpa adanya keinginan untuk berkonstribusi kepada kesejahteraan ekonomi masyarakat. Pemilihan bank Bank Central Asia (BCA) adalah karena BCA masuk pada peringkat Bank BCA masuk ke dalam tiga besar 50 Best Bank 20137', sedangkan Bank Muamalat Indonesia (BMI) menjadi Top Leader dibidangnya dengan predikat sebagai bank syariah terbaik di Indonesia dalam ajang penghargaan internasional yang digelar oleh Alpha Southeast Asia. ${ }^{8}$

Ekonomi Islam memiliki nilai dan karakteristik tersendiri, menurut Qardhawi, ia memiliki empat nilai utama, yaitu: Rabbaniyah (Ketuhanan), Akhlak, Kemanusiaan dan pertengahan. ${ }^{9}$

7 WBP. "Ini Daftar Bank Terbaik Versi Majalah Investor" http://www.beritasatu.com/bankdan-pembiayaan/117757-ini-daftar-bank-terbaik-versimajalah-investor.html, diakses pada 18 Desember 2013, Pukul 16:30 WIB.

${ }^{8}$ Ki001, "Bank Muamalat 5 Kali BerturutTurut Raih Penghargaan Bank Syariah Terbaik",http://www.kompasislam.com/2013/09/19/ba nk-muamalat-5-kali-berturut-turut-raih-penghargaanbank-syariah-terbaik/, diakses pada 18 Desember 2013, pukul 16:48 WIB

9 Yusuf Qardhawi. Peran Nilai dan Moral dalam Perekonomian Islam, Penerjemah didin 
Dari ke empat nilai tersebut pulalah muncul anggapan bahwa ekonomi Islam tidak hanya mementingkan keutamaan materi, tetapi juga keseimbangan dalam pelaksanaan kegiatan ekonomi salah satunya dengan jalan mensejahterakan masyarakat di lingkungan pelaku bisnis.

Selain itu pula, pertanggung jawaban dalam Islam sering disebutkan dalam al-Qur'an. Seperti perlunya moral pelaku bisnis dalam menjalankan kegiatan ekonomi, (QS al-Isra' (17): 35). Keharmonisan antara manusia dan lingkungan (QS al-Baqarah (2): 205). Serta anjuran untuk berbuat dermawan melalui kegiatan shadaqah dan qhard a/hasan (pinjaman kebaikan).

\section{B. Rumusan Masalah}

Penelitian ini akan membahas beberapa permasalahan tentang CSR, Yaitu: Bagaimana pelaksanaan CSR (Corporate Social Responsibility) pada Bank BCA dan BMI di Indonesia? Serta Bagaimana Pandangan Ekonomi Islam Terhadap Pelaksanaan CSR (Coorporate Social Responsibility) Bank BCA dan BMI di Indonesia?

\section{Tujuan Masalah}

Penelitian ini bertujuan untuk mengetahui pelaksanaan CSR (Corporate Social Responsibility) pada Bank BCA dan BMI di Indonesia. Serta untuk mengetahui

hafiduddin.dkk. (Jakarta: Robbani Press, 1997), hal. 23. dan menganalisa pelaksanaan CSR (Corporate Social Responsibility) menurut pandangan Ekonomi Islam pada perusahaan perbankan di Indonesia.

\section{D.Batasan Masalah}

Penelitian

ini

hanya

membahas tentang pelaksanaan Corporate Social Responsibility pada Bank BCA dan Bank BMI, kemudian penelitian membandingkan pelaksanaan CSR pada Bank BCA dan Bank BMI dengan perspektif Ekonomi Islam. Selain itu juga waktu penelitian ini hanya melihat pelaksanaan CSR pada Bank BCA dan Bank BMI pada periode 2012 menggunakan annual report dari ke dua Bank tersebut.

\section{LANDASAN TEORI}

\section{A. Konsep CSR (Corporate Social Responsibility)}

Menurut Frederick

dalam Dashurd mengatakan bahwa CSR adalah "...as a principle stating that Social corporations should be accountable for the Environmental effects of any of their actions on their community and environmen." ${ }^{10}$ Sehingga dapat dikatakan bahwa tanggung jawab sosial perusahaan merupakan suatu prinsip adanya tanggung jawab perusahaan untuk

\footnotetext{
${ }^{10}$ Alexander Dahlsurd. How Corporate Social Responsibility is Defined: an Analysis of 37 Definitions. Jurnal. Corp. Soc. Responsib. Environ. Mgmt. 15 , 1-13 (2008)Published online 9 November 2006 in Wiley InterScience (www.interscience.wiley.com) DOI : 10.1002/csr.132. hlm 11.
} 
menjaga kelestarian lingkungan, sosial, dan masyarakat dari setiap tindakan perusahaan yang merusak.

The World Bussiness Council For Suistanable Development (WBCSD), dalam Alexander Dahlsrud (2006), menjelaskan bahwa pengertian CSR adalah "Continuting commitment by bussiness to behave ethically and contribute economic development while improving the quality of the workforce and their family as well as of the local comminity and social at large ${ }^{\prime 11}$

\section{Penjelasan}

tersebut menekankan kepada perusahaan untuk selalu bertindak etis, legal, dan berkonstribusi untuk menigkatkan ekonomi, dengan meningkatkan kualitas hidup karyawan dan keluarganya sekaligus meningkatkan kualitas taraf hidup komunitas lokal, dan masyarakat.

Selanjutnya,

Carrol menjelaskan CSR dalam teorinya yang disebut dengan teori paragidma tanggung jawab sosial perusahaan. Menurutnya CSR perusahaan dapat dilihat berdasarkan empat jenjang yang menjadi satu kesatuan.

\footnotetext{
${ }^{11}$ Lihat di Alexander Dahlsurd., hlm, 7
}

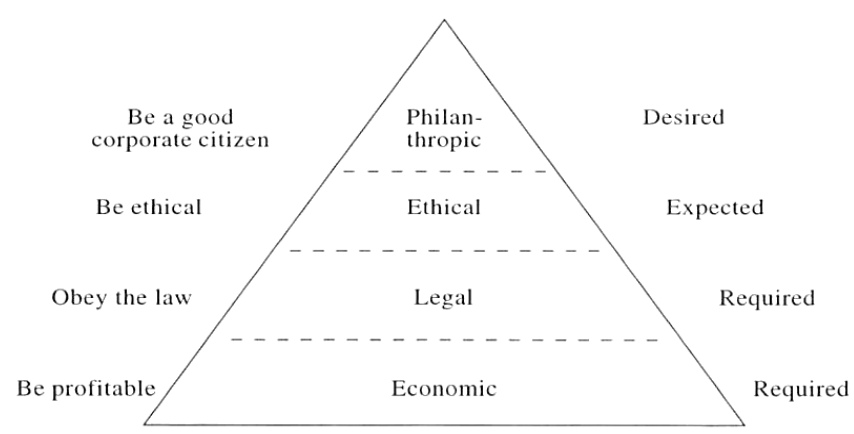

Gambar 1, Pyramid of

Corporate Social Responsibility ${ }^{12}$

Sumber: A.B Carrol, 1991

Piramida

tersebut

menjelasakan dasar pondasi perusahaan adalah menghasilkan laba untuk mempertahankan eksistensinya. Tanggung jawab ekonomi adalah tujuan utama perusahaan untuk memenuhi kebutuhan. Tetapi untuk memenuhi kebutuhan tersebut perusahaan diharuskan untuk mentaati ketentuan yang berlaku. Sehingga perusahaan tidak diperbolehkan melanggar hukum dan menghalalkan segala cara pada segi operasionalnya.

Tahapan berikutnya perusahaan diwajibkan bertanggung jawab secara etis. Perusahaan diwajibkan untuk memprakatekkan hal-hal yang baik dan benar sesuai dengan nilai etis di masyarkat. Pada akhirnya perusahaan harus

${ }^{12}$ A.B Carrol, The Pyramid of Corporate Social Responsibility: Toward the Moral Managment of Organitazational Stakeholders, Jurnal Business Horizons (Juli-Agustus, 1991), hlm 39-48. Lihat juga Mark S. Schwartz and A. Carrol Corporate Social Responsibility: A Three-Domain Approach. Jurnal. Business Ethics Quarterly, Volume 13, Issue 4. ISSN 1052-150X, hlm, 504. 
berkonstribusi kepada masyarakat untuk meningkatkan kualitas hidup masyarakat.

Berbagai pengertian di atas menunjuk pada suatu kesimpulan yang mengerucut pada sebuah kejelasan CSR, yaitu suatu kegiatan perusahaan tidak hanya berorientasi mencari laba saja disamping itu juga berkewajiban untuk menjaga keharmonisan dengan berbagai stake holder dan lingkungan disekitarnya sehingga dapat memberikan manfaat.

\section{B. Bentuk-bentuk CSR}

Teori Piramid CSR milik Carol memunculkan beberapa bentuk CSR. Bentuk CSR terdiri dari empat macam tanggung jawab yang dilaksanakan secara berkesinambungan oleh perusahaan, $^{13}$ yaitu: Pertama, Economic Responsibilities (Tanggung Jawab Ekonomi) Economic Responsibilities atau tanggung jawab ekonomi adalah dasar adanya perusahaan. Perusahaan sebagai lembaga yang berorientasi pada bisnis diharuskan untuk mendapatkan keuntungan bagi perusahaan. Kedua, Legal Responsibilities (Tanggung jawab Hukum), tanggung jawab hukum ini melekat pada perusahaan perbankan agar selalu mematuhi ketentuan-ketentuan perundang-

13 Lihat A.B Carrol, The Pyramid of Corporate Social Responsibility...... hal. 34-48 undangan yang berlaku sekaligus bersedia tidak melakukan hal yang bertentangan dengan hukum.

Ketiga, Ethical Responsibilities (Tanggung Jawab Etika) bertujuan untuk memenuhi standar, norma dan pengharapan Stakeholdr terhadap perusahaan perbankan. Selain itu juga bentuk ethical responsibilities adalah suatu bentuk menjunjung kearifan dan budaya lokal. Bentuk CSR yang terakhir adalah Philanthropic Responsibilities (Tanggung Jawab Kedermawanan) ini sebagai kontribusi perusahaan perbankan untuk berkontribusi pada menciptkan kesejahteraan masyarakat secara mikro dan makro sosial.

\section{Landasan Pelaksanaan CSR di Indonesia}

Beberapa Peraturan yang terkait dengan CSR di Indonesia diantaranya adalah Undang-Undang Republik Indonesia Nomor 23 tahun 1997 tentang Lingkungan Hidup, Undang-Undang Republik Indonesia Nomor 8 tahun 1999 tentang perlindungan konsumen, UndangUndang Republik Indonesia nomor 5 tahun 1999 Tentang praktek Larangan Monopoli Dan Persaingan Usaha tidak sehat dan lain sebagainya.

Kemudian Peraturan lain yang menjadikan kegiatan CSR yang dahulu bersifat voluntary kini menjadi bersifat mandatory 
adalah Undang - Undang Republik Indonesia No.19 tahun 2003 Tentang Badan Usaha Milik Negara, Keputusan Menteri BUMN Nomor Kep -236/MBU/2003, Surat Edaran Menter BUMN No. SE.433/MBU/2003, Undang-Undang RepublikIndonesia Nomor 25 Tahun 2007 Tentang Penanaman Modal.

Selain Undang-Undang di atas, juga terdapat Undang-Undang Republik Indonesia No 40 Tahun 2007, pasal 1 ayat 3 lebih rinci menjelaskan bahwa yang dimaksud CSR adalah komitmen perseroan untuk berperan serta dalam pembangunan ekonomi berkelanjutan guna meningkatkan kualitas kehidupan dan lingkungan yang bermanfaat, baik bagi korporat, komuniti tempatan maupun pada masyarakat umumnya. ${ }^{14}$ Selanjutnya, pada pasal 74 ayat 2 menyebutkan bahwa tanggung jawab sosial dan lingkungan merupakan kewajiban perseroan yang dianggarkan dan diperhitungkan dari sebagai biaya perseroan yang pelaksanaannya dilakukan dengan memperhatikan kepatutan dan kewajaran. ${ }^{15}$

Hal itu juga terdapat pada Peraturan Pemerintah No 47 Tahun 2012 pada pasal 5 ayat 2 tentang tanggung jawab sosial dan

${ }^{14}$ Undang-Undang Republik Indonesia No 40 Tahun 2007, pasal 1 ayat 3 tentang Perseroan Terbatas, hlm. 19.

${ }^{15}$ Ibid. lingkungan perseroan terbatas, menyebutkan bahwa realisasi anggaran untuk pelaksanaan tanggung jawab sosial dan lingkungan perseroan diperhitungkan sebagai biaya perseroan. ${ }^{16}$

\section{Perusahaan Sektor Perbankan di Indonesia}

Dilihat dari UU perbankan No. 7 tahun 1992, maka perusahaan perbankan atau disebut perbankan memiliki pengertian badan usaha yang menghimpun dana masyarakat dalam bentuk simpanan dan menyalurkannya kepada masyarakat dalam rangka meningkatakan taraf hidup rakyat banyak. ${ }^{17}$

\begin{tabular}{llr}
\multicolumn{2}{c}{ Di Indonesia, } & Perbankan \\
adalah salah satu & bentuk \\
perusahaan yang & memiliki peran \\
strategis & untuk & memberikan
\end{tabular}
pemberdayaan masyarakat. Bank memiliki visibilitas yang tinggi, karena operasionalnya yang erat dengan kehidupan. Pelaksanaan CSR bank swasta Indonesia diatur oleh Undang-Undang Nomor 47 Tahun 2012 tentang Tanggung Jawab Sosial dan Lingkungan Perseroan Terbatas (PT), sedangkan bank pemerintah diatur lebih rinci dalam Peraturan Menteri Negara Badan Usaha Milik

${ }^{16}$ Peraturan Pemerintah No 47 Tahun 2012 pada pasal 5 ayat 2 tentang tanggung jawab sosial dan lingkungan perseroan terbatas, hlm. 6

17 Lihat, Undang-Undang No. 7 Tahun 1992, pasal 1 , butir 1 , pengertian perbankan. 
Negara No. Per-05/MBU/2007 tentang Program Kemitraan Badan Usaha Milik Negara dengan Usaha Kecil dan Program Bina Lingkungan (PKBL). PKBL BUMN dibentuk secara khusus untuk menjalankan salah satu tujuan negara yaitu mengelola sumberdaya alam dan aset negara yang diperuntukkan demi kepentingan dan kesejahteraan hidup rakyat Indonesia.

Kemudian, lebih rinci lagi dalam undang-undang No. 21 tahun 2008 pasal 1 menjelasakan dua bentuk perbankan, yang terdiri dari dua jenis, yaitu: Pertama, Bank Konvensional, merupakan bank yang menjalankan kegiatan usahanya secara konvensional yang terdiri atas Bank Umum Konvensional dan Bank Perkreditan Rakyat Konvensional. Kedua, Perbankan Syariah, merupakan bank yang menjalankan kegiatan usahanya berdasarakan prinsip syariah. Adapun Bank Syariah terdiri dari Bank Umum Syariah dan Bank Pembiayaan Rakyat Syariah.

\section{E. Tinjauan CSR dalam Ekonomi Islam}

\section{Berbebeda}

pandangan humanistis Barat, pandangan Islam mengenai CSR menggunakan pendekatan yang bersifat holistis. Menawarkan konsep yang didasarkan pada integralistic spriritual, yang didasakan pada al-Qur'an dan
Sunah. ${ }^{18}$ Hal ini adalah suatu konsep yang mendasar pada pelaksanaan CSR dalam ekonomi Islam.

Dalam presfektif Islam, CSR merupakan realisasi dari konsep ajaran al-Ihsan sebagai puncak dari ajaran etika yang sangat mulia. Disamping itu, CSR merupakan implikasi dari ajaran kepemilikan dalam Islam, Allah adalah pemilik mutlaq (Haqiqiyah) sedangkan manusia hanya sebatas pmilik sementara (temporer) yang berfungsi sebagai penerima amanah. ${ }^{19}$ Sebagai seseorang yang menerima amanah maka individu maupun kelompok harus dapat menjadi khalifa yang dapat berbuat keadilan, bertanggung jawab dan melakukan perbuatan yang bermanfaat.

CSR

dalam

Islam

memandang tentang hubungan manusia dalam dirinya sendiri dan lingkungan sosialnya, dapat dipresentasikan dengan empat aksioma, ${ }^{20}$ yaitu kesatuan (tauhid), keseimbangan

(equilibrium), kehendak bebas (free will), dan tanggung jawab (responsibility). Seperti yang telah diungkapkan oleh

\footnotetext{
${ }^{18}$ Asyrar Wajdi Dusuki. What Does Islamic Say About Corporate Cosial Responsibility (CSR)?. Jurnal, Review of Islamic Economics, Volume 12, Number 1, May 2008., hal 11

${ }_{19}$ Muhammad Djakfar, Etika Bisnia dalam Perspektif Islam, Malang: UIN Malang Press, 2007, Hlm. 160

20 Syed Nawab Haidar Naqvi, Menggagas Ekonomi Islam, Yogyakarta: Pustaka Pelajar, 2003, Hlm. 37
} 
Naqfi, pandangan Islam tentang manusia dala hubungan dirinya sendiri dan lingkungan sosialnya, dapat dipresentasikan dengan empat aksioma tersebut. ${ }^{21}$ Ini adalah konsensus yang mendasari pandangan sosial ekonomi muslim, sehingga aksioma-aksioma tersebut tidak dapat dipisahkan.

\section{F. Konsep-Konsep CSR dalam Ekonomi Islam}

1. Masalahah dan Maqhasid Syariah dalam CSR

Penerapan CSR dalam Islam pula sangat berkaitan dengan konsep Maqhasid Syariah dan Maslahah seperti yang dikemukakan oleh Muhammad (2010) dan Dusuki dan Abdullah (2007) ${ }^{22}$. Sehingga dapat dikatakan bahwa dalam al-Qur'an dan al-Sunnah adalah sebuah dalil yang menunjukkan adanya maslahah meskipun secara tidak langsung, tetapi ada beberapa dalil yang mengindikasikan adanya eksistensi maslahat dalam syari'at Islam.

Jika ditinjau dari kaca mata maqhasidu al-Syariah dan al-Maslahah, maka akan diambil dasar bahwa dalam Islam dalam hal ini hukum Islam secara kulaitatif dan kuantitatif melindungi kemaslahatan

${ }^{21}$ Ibid.,

${ }^{22}$ Lihat Asyraf W Dusuki dan Nurdianawati I Abdullah. Maqhasid al-Shari'ah,....., hal 25-48. sekaligus menolak atau meninggalkan maslahah bagi individu di masyarakat, yang melindungi lima aspek, yaitu aspek agama (hifzu ad-din), jiwa (hifzu an-nafs), keturunan (hifzu an-nasl), akal (hifzu al-'aql), dan harta (hifzu al-mal). ${ }^{23}$ Konsekuensi logis prinsip ini telah memberikan pemahaman bahwa dalam konteks mafsadah (kerusakan) yang terjadi dalam suatu kegiatan perekonomian adalah hal yang bersifat kontradiktif, karena hal ini berakibat merusak ketidak seimbangan, bahkan keberlangsungan kehidupan manusia. Sehingga pada akhirnya akan mengancam alkulliyat al-khams atau adhdharurat al-hams tersebut.

Dalam menjaga maqhasid syari'ah terdapat tiga tingkatan penjagaan, yaitu dlaruriyah, hajjiyah, dan tahsiniyah. Jika Dlaruriyah adalah bentuk kemaslahatan yang harus diutamakan, atau kebutuhan primer yang mendesak untuk dipenuhi masyarakat maupun oleh masing-masing individu.

23 Menurut sebagian pendapat bahwa alkuliyyah al-khamsah yang telah dirumuskan oleh para ulama ahli klasik sudah tidak cukup lagi jika sebatas lima kebutuhan primer pada masa sekarang, Sehingga dibutuhkan inovasi dalam meletakkan kebutuhankebutuhan primer kekinian sebagai maqhasid syariah, seperti hak mendapat pekerjaan, pangan, sandang dan papan, hak pendidikan hak pengobatan, dan hak kebebasan berpendapat, berpolitik, pemilu dan suksesi, dan lain sebagainya sangat perlu adanya. 
Jika terabaikan maka akan mengakibatkan kerusakan atau destruktif bagi manusia sendiri ataupun lingkungan.

\section{Paradigma Takwa (Taqwa- Centric)}

Konsep CSR dalam Islam diperkenalkan oleh Dusuki tentang paradigma Takwa. $^{24}$ Menurutnya, Takwa adalah pusat untuk memahami Syariah. Hal ini menjadikan seorang muslim melaksanakan tujuan syariah. ${ }^{25}$ Sehingga Pradigma Takwa ini di harapkan dapat mencapai tujuan Falah yang hakiki. Paradigma Takwa bertindak sebagai elemen inti dalam menerapkan CSR dari sudut pandang Islam.

Dari konsep ini juga, muncul posisi Islam dalam konsep CSR sehingga akan muncul beberapa rangkaian dimulai dari sikap tidak bertanggung jawab perusahaan hingga sikap tanggung jawab perusahaan dalam melaksanakan CSR berdasarkan God-consciousness (takwa sentris). ${ }^{26}$

${ }^{24}$ Asyrar Wajdi Dusuki. What Does Islamic Say About Corporate Cosial Responsibility (CSR)?., hal 13.

${ }^{25}$ Ibid.,

${ }^{26}$ Asyrar Wajdi Dusuki. What Does Islamic Say About Corporate Cosial Responsibility (CSR)?., hal 13.

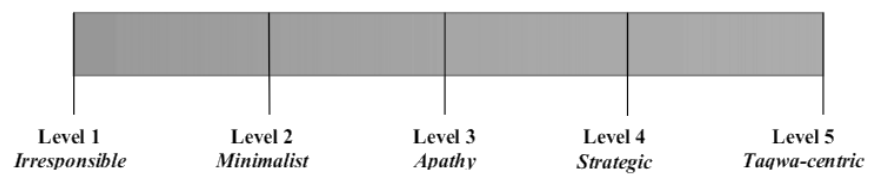

Gambar 2. Islam Position in CSR Continuum

Sumber: Dusuki, 2008

Gambar

tersebut

menunjukkan rangkaian level dalam pelaksanaan CSR oleh perusahaan. Level 1 Irresponsible, level ini menunjukkan bahwa perusahaan tidak bertanggung jawab atau melanggar hukum. Level 2 Minimalist, level ini menunjukkan perusahaan melaksanakan aturan-aturan atau undang-undang yang berlaku hanya sekedarnya saja (minimalis). Level 3 Apathy, di level ini perusahaan tidak saja melaksanakan kegiatan sesuai aturan-aturan dan undangundang yang berlaku tetapi juga menjalankan kegiatan bisnis dengan moral, benar, adil, dan menghindar dari kerugian. Pada Level 4, Strategic, menunjukkan bahwa perusahaan memenuhi tanggung jawab sosial, termasuk di dalamnya tanggung jawab philantropi atau altruistik. Pada level terakhir, Level 5 TaqwaCentric, level ini mewujudkan perusahaan bertanggung jawab sosial tidak hanya didasarkan pada keyakinan tanggung jawab sosial tanpa melihat kondisi 
keuangan positif atau negatif. Keyakinan ini di dasarkan oleh ajaran Islam dan dipandu dengan Syariah. ${ }^{27}$

\section{METODOLOGI PENELITIAN}

Jenis Penelitian yang digunakan pada penelitian ini merupakan penelitian deskriptif kualitatif. Penelitian deskriptif adalah penelitian yang bermaksud untuk membuat pencandraan (deskripsi) mengenai situasi-situasi atau kejadian-kejadian. ${ }^{28}$

Penelitian kualitatif deskriptif bertujuan untuk memahami fenomena tentang apa yang dialami oleh subjek penelitian misalnya perilaku, persepsi, motivasi, dan tindakan secara holistik dan dengan cara deskriptif dalam bentuk katakata dan bahasa, pada suatu konteks khusus yang alamiah dan memanfaatkan berbagai metode alamiah. ${ }^{29}$ Penelitian Metode kuantitatif dirasa kurang tepat dan sesuai untuk penelitian ini. Hal ini dikarenakan penelitian ini tidak menggunakan angka-angka sebagai indikator variabel penelitian untuk menjawab permasalahan penelitian.

Penelitian ini juga termasuk ke dalam penelitian komparatif.

\footnotetext{
${ }^{27}$ Ibid.

28 Supardi, Metodologi Penelitian Ekonomi Bisnis, (Yogyakarta, UII Press, 2005), hal, 34.

29 Moleong, Lexy. 2002. Metodologi Penelitian Kualitatif. Bandung: PT. Remaja Rosdakarya. 2002, hal 6
}

Penerapan metode kualitatif secara komparatif adalah melakukan analisis untuk mencari dan menemukan persamaan-persamaan dan perbedaan- perbedaan fenomena. ${ }^{30}$ Penelitian ini berusaha untuk menghasilkan data deskriptif analitis dari Annual Report mengenai laporan Corporate Social Responsbility diterbitkan oleh Bank BCA dan bank Muamalat periode 2012.

HASIL PENELITIAN DAN PEMBAHASAN

\section{A. Implementasi CSR Pada Bank BCA} dan BMI di Indonesia Tahun 2012

Pelaksanaan CSR Bank BCA pada 2012 berpijak pada konsep pemberdayaan masyarakat yang berkelanjutan. Adapun tiga program CSR yang dilaksanakan oleh Bank BCA pada tahun 2012, yaitu Bakti BCA- Solusi Cerdas BCA, Bakti BCASolusi Sinergi BCA, dan Bakti BCASolusi Bisnis Unggul BCA. ${ }^{31}$

${ }^{30}$ Arikunto, Suharsimi. Prosedur Penelitian Suatu Pendekatan dan Praktik, (Jakarta: Bina Kasara, 1989) hal, 197.

31 Bank BCA, Laporan Tahunan Bank BCA 2012. (Jakarta: PT Bank BCA Tbk, 2012), hal 106. 
Tabel 1. Pelaksanaan Program CSR Bank BCA Tahun 2012

\begin{tabular}{|c|l|l|l|}
\hline No & Fokus Program & \multicolumn{1}{|c|}{$\begin{array}{l}\text { Program CSR Bank } \\
\text { BCA Tahun 2012 }\end{array}$} & Jumlah Dana \\
\hline 1 & Solusi Cerdas & $\begin{array}{l}\text { 1. PPA non Degree } \\
\text { 2. Beasiswa Bakti BCA } \\
\text { 3. Bakti B } \\
\text { terintegrasi BCA } \\
\text { 4. Kemitraan } \\
\text { 5. Pemagangan bakti } \\
\text { BCA }\end{array}$ & \\
\hline 2 & Sinergi BCA & $\begin{array}{l}\text { 1. Budaya } \\
\text { 2. Kesehatan } \\
\text { 3. Lingkungan } \\
\text { 4. Olah raga } \\
\text { 5. Empati } \\
\text { 6. Sumbangan Lain- } \\
\text { lain }\end{array}$ & \\
\hline 3 & $\begin{array}{l}\text { Bisnis Unggul } \\
\text { BCA }\end{array}$ & \\
\hline \multicolumn{2}{|c|}{ Jumlahitas } & Total \\
\hline
\end{tabular}

Sumber: Diolah dari Laporan Tahunan CSR Bank BCA Tahun 2012

Selain Ketiga Program CSR Bank BCA di atas, BCA juga Berkomitmen tinggi dalam perlindungan kerja terhadap karyawan dan para nasabah. Pertama, pada Perlindungan Terhadap Karyawan, Manajemen Sumber Daya Manusia di BCA mengedepankan Asset Human Capital yang menyeluruh, sehingga Bank BCA menjamin hak-hak dan kewajiban setiap karyawan seperti dalam perindungan kerja karyawan, memperhatikan

Kesehatan Karyawan, Kesejahteraan memperhatikan Karyawan, mengedepankan Keselamatan Kerja Karyawan, rendahnya Turnover Karyawan.

Dilain pihak pelaksanaan CSR pada Bank BMI Pada tahun 2012, fokus utama pelaksanaan CSR Bank Muamalat pada tahun 2012 adalah program-program di bidang pengembangan masyarakat, pembiayaan mikro dan bantuan sosial, serta pada bidang lainnya. ${ }^{32}$

${ }^{32}$ Bank Mumalat, Laporan Tahunan Bank Muamalat 2011, (Jakarta: PT Bank Muamalat Indonesia Tbk, 2011), hal 274. 
Tabel 2. Pelaksanaan Program CSR BMI Tahun 2012

\begin{tabular}{|c|c|c|c|}
\hline No & Jenis Program & $\begin{array}{c}\text { Penerima } \\
\text { Manfaat } \\
\text { Program }\end{array}$ & $\begin{array}{c}\text { Bentuk Fasilitas/Nilai } \\
\text { Nominal yang } \\
\text { diberikan }\end{array}$ \\
\hline 1 & $\begin{array}{l}\text { Pemberdayaan Ekonomi } \\
\text { 1. KUM3 dan KJKS } \\
\text { KUM3 } \\
\text { 2. Pengembangan } \\
\text { LKMS } \\
\text { 3. Pemeberdayaan } \\
\text { Wakaf }\end{array}$ & $\begin{array}{l}11 \text { KJKS dan } \\
206 \\
\text { kelompok }\end{array}$ & 1.800 .000 .000 \\
\hline 2 & $\begin{array}{l}\text { Pendidikan } \\
\text { 1. Orphan Kafala } \\
\text { 2. Program ISS } \\
\text { 3. Program MMS. } \\
\text { 4. Beasiswa Pendidikan } \\
\end{array}$ & 817 siswa & $\begin{array}{r}\text { Rp } 10.900 .000 .000 \\
2.000 .000 .000 \\
2.300 .000 .000 \\
2.100 .000 .000 \\
\end{array}$ \\
\hline 3 & $\begin{array}{l}\text { Bidang Sosial } \\
\text { 1. Program santun } \\
\text { 2. Aksi Tanggap Muamalat } \\
\text { 3. Berbagi Cahaya } \\
\text { Ramadhan } \\
\text { 4. Berbagi Cahaya Qurban } \\
\text { 5. Komunitas Sehat } \\
\text { Muamalat }\end{array}$ & $\begin{array}{l}\begin{array}{l}3.566 \text { orang } \\
\text { Korban } \\
\text { bencana }\end{array} \\
13.857 \\
\text { orang } \\
153 \text { kader }\end{array}$ & $\begin{array}{r}\text { Rp } 1.152 .000 .000 \\
528.000 .000 \\
3.400 .000 .000 \\
\\
592.014 .856 \\
311.000 .000\end{array}$ \\
\hline 4 & $\begin{array}{l}\text { Bidang lain-lain } \\
\text { 1. Program CSR } \\
\text { 2. Program Non-ZIS }\end{array}$ & & 552.969 .400 \\
\hline \multicolumn{3}{|c|}{ Jumlah } & $\begin{array}{l}+/-\mathrm{Rp} \\
25.635 .984 .256\end{array}$ \\
\hline
\end{tabular}

Sumber: Diolah dari Laporan Tahunan CSR BMI Tahun 2012

Selain program tersebut, BMM juga memiliki program Non-ZIS (Zakat, Infaq, Sedekah), berupa pembangunan fasilitas MCK di
Semarang, Sanitasi air bersih di Brebes, Kampung Hijau Muamalat di Bengkulu, kampanye Go Green penanaman mangrove di Pulau 
Lancang, dan Pembangunan Rumah Sakit di Solo. ${ }^{33}$

\section{B. Perbandingan Pelaksanaan CSR Bank BCA dan Bank BMI di Indonesia}

Setalah melihat implementasi CSR pada Bank BCA dan Bank BMI didapati beberapa persamaan dan perbedaan pelaksanaan pelaksanaan CSR pada Bank BCA dan Bank Muamalat. Berikut adalah beberapa persamaan dan perbedaan pelaksanaan CSR Bank BCA dan Bank Muamalat Indonesia pada tahun 2012.

1. Persamaan Pelaksanaan CSR Bank BCA dan Bank Muamalat Realisasi Program CSR Bank BCA dan Bank Muamalat menunjukkan bahwa program yang terealisiasi pada CSR bank BCA dan Bank Muamalat pada tahun 2012 hampir sama, yaitu terpusat pada program pemberdayaan ekonomi, donasi dibidang pendidikan, kesehatan, dan donasi untuk berbagai bencana di Indonesia.

Jika dilihat di sektor pelaksanaan CSR Bank BCA dan Bank Muamalat, maka sektor yang selalu dilaksanakan adalah sektor pendidikan, bantuan sosial, kesehatan, dan pada sektor lingkungan mulai dilaksanakan pada tahun 2010 untuk bank BCA dan tahun 2011 pada Bank Muamalat.

Hal ini telah sesuai dengan konsep pelaksanaan CSR berdasarkan Triple Bottom Line, yaitu pelaksanaan tanggung jawab sosial yang menekankan pada aspek Profit, People, dan Planet. Dimana perusahaan diharuskan untuk bertanggung jawab yang bersifat sosial dan lingkungan secara berkesinambungan dan saling mengikat.

2. Perbedaan Pelaksanaan CSR Bank BCA dan Bank BMI

Ada perbedaan mendasar pelaksanaan CSR Bank BCA dan Bank BMI adalah sebagai berikut: Pertama, Landasan dan Prinsip Pelaksanaan CSR Bank BCA dan Bank Muamalat Indonesia. Pada Bank Muamalat prinsip dan landasan sangat dipengaruhi oleh ajaran agama Islam, sehingga realisasi program CSR Bank Muamalat sangat dipengaruhi aspek religius hal ini dapat dilihat pada visi dan misi CSR Bank Muamalat. ${ }^{34}$

Sehingga pelaksanaannya tidak lepas dengan kegiatan religius. Adapaun alasan tersebut dapat dijabarkan pada beberapa poin penting yang ditemui. Pertama, Bank Muamalat Indonesia adalah Bisnis yang

${ }^{33}$ Ibid., 293

34 Bank Muamalat, Laporan Tahunan 2012,., hlm 24 
berbasis dengan Syari'ah.

Sehingga pelaksanaannya pun tidak lepas untuk kegaitan agama. Selain itu juga, pelaksanaan CSR atau tanggung jawab sosial Bank Muamalat kebanyakan di danai oleh dana ZISWAF (Zakat, Infaq, Sedekah, dan Wakaf). ${ }^{35}$ Sehingga pelaksanaannya tidak terlepas kepada 8 Asnaf dan selalu menekankan kegiatan yang lebih agamis.

Sedangkan pelaksanaan CSR pada Bank BCA sangat berbeda. Jika dilihat dari visi dan misi Bank BCA maka akan ditemukan bahwa pelaksanaan CSR Bank BCA hanya berdasar pada memberikan pendanaan dan menyediakan bantuan logistik melalui berbagai program CSR untuk sektor pendidikan, edukasi perbankan, pemberdayaan Usaha Kecil Menengah (UKM), kesehatan, pelestarian lingkungan, dan bantuan penanggulangan bencana alam. ${ }^{36}$ Sehingga pengaruh agama dalam pelaksanaan CSR sangat minim

\footnotetext{
${ }^{35} \mathrm{Hal}$ ini dikarenakan pelaksana CSR atau tanggung jawab sosial Bank Muamalat dilaksanakan oleh lembaga Baitul Mal Muamalat (BMM) dibawah naungan Bank Muamalat. Dan lembaga tersebut adalah lembaga Amil Zakat, sehingga pelaksanaan kegiatannya bersumber dari dana ZIS Bank Muamalat, karyawan dan nasabah, dana CSR, dana sosial lainnya, dan dana non halal. Untuk lebih jelasnya dapat dilihat Bank Muamalat, Laporan Tahunan 2011,., hlm 258-259.

http://www.bca.co.id/id/about/baktibca/bakti_bca.jsp, diakses pada 27 Desember 2013, jam 12.53 .
}

bahkan bisa dikatakan tidak ada. Hanya pengaruh ekonomi yang dominan.

Kedua, dari sisi Pelaksana kegiatan CSR. CSR atau tanggung jawab sosial bank Muamalat diserahkan kepada lembaga Baitul Maal Muamalat (BMM). BMM sendiri merupakan unit pengelola dana ZIS dan dana sosial kebijakan. ${ }^{37}$ Sedangkan pelaksana kegiatan CSR Bank BCA langsung dibawah Bank BCA sendiri. Sedangkan pada Bank Muamalat, pelaksanaan CSR diberikan kepada lembaga dibawah naungan Bank Muamalat. Pelaksana program CSR Bank BCA adalah di bawah program "Bakti $\mathrm{BCA}^{\prime \prime 38}$ langsung di bawah manajemen Bank BCA. Dalam artian, bahwa pelaksanaan CSR Bank BCA adalah langsung dilaksanakan oleh Bank BCA sendiri.

Ketiga, Fokus Pelaksanaan
CSR Bank BCA dan Bank Muamalat Indonesia. Pelaksanaan CSR Bank BCA berkomitmen berperan aktif dalam meningkatkan kesejahteraan dan standar hidup rakyat Indonesia. Fokus kegiatan CSR Bank BCA dari tahun ke tahun mengalami

http://www.muamalatbank.com/home/about/subsid ary_bmm, diakses pada 27 Desmeber 2013, jam 11.15 .

38 http://www.bca.co.id/id/about/baktibca/bakti_bca.jsp, diakses pada 27 Desember 2013 , jam 11.24 
perubahan yang semakin baik. Pada tahun 2012, fokus CSR BCA juga lebih luas, selain pendidikan dan kesehatan, pemberdayaan ekonomi dan pelestarian lingkungan pun mulai dilaksanakan oleh CSR Bank BCA. ${ }^{39}$ Di sisi lain, Bank Muamalat dalam pelaksanaan CSRnya juga berkoitmen untuk mewujudkan tatanan masyarakat yang adil dan makmur sejalan dengan prinsipprinsip dasar ekonomi syariah. Adapun fokus kegiatan CSR pada Bank Muamalat pada 2007 sampai dengan 2009 fokus utamanya adalah pada pembinaan dan dukungan pada usaha mikro, ${ }^{40}$ meskipun pada tahun-tahun tersebut terdapat program yang terkonsentrasi pada pendidikan dan bantuan sosial baik berupa bantuan bencana alam maupun kesehatan. Pasca penerapan CSR 2009, yaitu pada 2010 CSR Bank BCA mulai menambah fokus program CSR mereka yaitu dengan pelestarian lingkungan dengan program Non-ZIS. ${ }^{41}$

Perbedaan

terakhir

adalahSumber Dana Pelaksanaan CSR.

Pada Bank BCA sumber dana pelaksanaan Program CSR Bank BCA bersumber dari 2 pos 218-233

${ }^{39}$ Bank BCA, Laporan Tahunan 2012., hal

40 Lihat Bank Muamalat, laporan Tahunan Bank Muamamalat 2009., hal-86

${ }^{41}$ Bank Muamalat, laporan Tahunan Bank Muamamalat 2010., hal-228 dana, yaitu dari dana CSR Bank $\mathrm{BCA}^{42}$, Bantuan Masyarakat. Bantuan dari masyarakat untuk program bantuan sosial seperti bencana alam dan lain sebagainya. Sedangkan pada Bank Muamalat, sumber dana CSR atau Tanggung Jawab Sosial Bank Muamalat bersumber dari berbagai pos dana. Sumber dana pelaksanaan program sosial Baitul Maal Muamalat bersumber dari 6 pos dana, antara lain adalah bersumber dari: Pertama, Dana Zakat, Infak, dan Sedekah. ${ }^{43}$ Kedua, Dana Wakaf Pada tahun 2010 BMM mulai menggalakkan program wakaf berupa Wakaf Tunai Muamalat. ${ }^{44}$ Ketiga, Dana Non ZIS. ${ }^{45}$ Dana NON-ZIS Bank Muamalat adalah dana yang bersumber dari pendapatan Bank Muamalat atas pendapatannya di bank-bank konvensional yang tidak dapat diakui sebagai pendapatan sesuai dengan prinsip syariah. ${ }^{46}$
42 Bank BCA, Laporan Tahunan Bank BCA Tahun 2012., hal 229.

${ }^{43}$ Ibid.
${ }^{44}$ Ibid., hal 230.
${ }^{45}$ Ibid., hal 228

46 Bank Muamalat, Laporan Tahunan Bank Muamalat 2011., hal 275 
Tabel 3 Perbandingan Pelaksanaan CSR Bank BCA dan BMI

\begin{tabular}{|c|c|c|c|c|}
\hline \multirow{2}{*}{ No } & \multicolumn{2}{|c|}{$\begin{array}{c}\text { Kelebihan Pelaksanaan } \\
\text { CSR }\end{array}$} & \multicolumn{2}{|c|}{ Kelemahan Pelaksanaan CSR } \\
\hline & BCA & BMI & $\mathrm{BCA}$ & BMI \\
\hline 1 & $\begin{array}{l}\text { Sesuai } \\
\text { Triple } \\
\text { Bottom } \\
\text { line }\end{array}$ & $\begin{array}{l}\text { Sesuai Triple } \\
\text { Bottom line }\end{array}$ & $\begin{array}{l}\text { Belum sesuai } \\
\text { core } \\
\text { bussines }\end{array}$ & $\begin{array}{l}\text { Belum sesuai } \\
\text { core bussines }\end{array}$ \\
\hline 2 & $\begin{array}{l}\text { perlindung } \\
\text { an pekerja }\end{array}$ & $\begin{array}{l}\text { Tanggung } \\
\text { jawab bersifat } \\
\text { Vertikal dan } \\
\text { Horizontal }\end{array}$ & $\begin{array}{l}\text { Banyak } \\
\text { program } \\
\text { philantropi }\end{array}$ & $\begin{array}{l}\text { Banyak } \\
\text { program } \\
\text { philantropi }\end{array}$ \\
\hline 3 & $\begin{array}{l}\text { Sumber } \\
\text { dana jelas }\end{array}$ & $\begin{array}{l}\text { Kegiatan } \\
\text { sosial sangat } \\
\text { melekat }\end{array}$ & $\begin{array}{l}\text { Hanya motif } \\
\text { bisnis saja }\end{array}$ & $\begin{array}{l}\text { Sumber dana } \\
\text { bias }\end{array}$ \\
\hline 4 & & $\begin{array}{l}\text { kegaamaan } \\
\text { sangat } \\
\text { melekat }\end{array}$ & $\begin{array}{l}\text { keagamaan } \\
\text { Minimalis }\end{array}$ & \\
\hline
\end{tabular}

\section{Pelaksanaan CSR Bank BCA dan BMI Perspektif Ekonomi Islam}

Meskipun dalam tataran konsep dapat dilihat perbedaan pada pelaksanaan CSR pada Bank Konvensional dan Bank Syariah, tetapi dalam tataran pelaksanaan perlu dilihat lebih dalam lagi apakah benar konsep telah sesuai dengan pelaksanaannya. Dilihat pada pelaksanaan CSR Bank BCA pada tahun 2012, maka pelaksanaan CSR Bank BCA masuk pada tingkatan pelaksanaan CSR yang bersifat Strategic. pelaksanaan CSR yang bersifat Strategic adalah perusahaan memenuhi tanggung jawab sosial, termasuk bertanggung jawab secara filantropis atau altruistik. ${ }^{47}$ Adapun pelaksanaan CSR Bank BCA yang menujukkan pada level ini adalah program PPA-non degree, pengembangan $L P B$, donasi dibidang pendidikan dan kesehatan, serta berkonstribusi pada lingkungan. ${ }^{48}$

Sedangkan pelaksanaan CSR Bank Muamalat pada tahun 2012 menunjukkan pada pelaksanaan CSR yang bersifat Taqwa-Centric. Pelaksanaan CSR yang bersifat Taqwa-Centric adalah, perusahaan mewujudkan tanggung jawab sosial didasarkan pada keyakinan bahwa perusahaan harus bertanggung

${ }^{47}$ Lihat Asyrar Wajdi Dusuki. What Does Islamic Say About Corporate Cosial Responsibility (CSR)?. Jurnal, Review of Islamic Economics, Volume 12, Number 1, May 2008., hal 20.

${ }^{48}$ Bank BCA, Laporan Tahunan Bank BCA Tahun 2012., hal 219-299 
jawab secara sosial tanpa konsekuensi kondisi keuangan positif atau negatif. ${ }^{49}$ Dengan asumsi dana yang digunakan untuk kegiatan tanggung jawab sosial tersebut adalah dana ZISWAF perusahaan, karyawan dan masyarakat dan dana sosial dari berbagai lembaga.

Tapi jika dilihat dari sisi dana CSR Bank Muamalat sendiri, maka didapati bahwa pelaksanaan CSR dengan menggunakan dana CSRBank Muamalat hanya bersifat Apathy. Pelaksanaan CSR yang bersifat Apathy adalah beroperasi menurut aturan-aturan yang berlaku atau sesuai dengan hukum yang berlaku, pada saat yang sama melakukan bisnis sesuai moral, melakukan apa yang benar, adil dan menghindari kerugian. ${ }^{50}$ Perilaku Aphaty juga beciri pada ketidakpedulian, dalam arti bahwa tidak ada upaya strategis bagi perusahaan untuk terlibat dalam kegiatan CSR. Hal ini dikarenakan pelaksanaan tanggung jawab sosial (CSR) -dengan dana CSR- dari tahun ke tahun mengalami perubahan program dan terkesan hanya bersifat pelengkap saja. ${ }^{51}$ Sedangkan program dengan dana CSR pada tahun 2012 untuk operasi Katarak, Peresmian Kampung Hijau

${ }^{49}$ Lihat Asyrar Wajdi Dusuki. What Does Islamic Say About Corporate Cosial Responsibility (CSR)?, hal 20.

${ }^{50}$ Ibid.,

${ }^{51}$ Bank Muamalat, Laporan Tahunan

Bank Muamalat Tahun 2012., hal 274-275.
Muamalat, donasi alat produksi, acara SBL, serta bantuan wirausaha. ${ }^{52}$

Dalam

kegiatan

jasa

keuangan, Core Bussiness institusi perbankan dapat dibagi menjadi dua aspek fungsi, yaitu fungsi akumulasi dana publik dan fungsi intermediasi dalampenyaluran kredit atau pembiayaan kegiatan usaha atau projek-projek tertentu. ${ }^{53} \mathrm{Hal}$ ini menunjukkan bahwa seharusnya kegiatan CSR perusahaan haruslah sesuai dengan core bussiness yaitu di bidang financial dengan mengedepankan produk yang sesuai dengan kemaslahatan sosial dan kelestarian lingkkungan. Seharusnya produk yang dihadirkan adalah produk yang ramah baik sosial ataupun lingkungan.

Nilai-nilai yang terkandung dalam maslahah dan maqhasid syariah agar dapat teradopsi dengan pelaksanaan CSR Bank BCA dan Bank Muamalat, maka penulis akan membahas pada pelaksanaan pada Bank BCA dan Bank Muamalat harus melihat pada core bussiness perusahaan. Menurut hemat penulis, bahwa al-dloruriyat perbankan yang menyangkut masalah pelaksanaan CSR adalah pelaksanaan prinsipprinsip tentang transparasi, akuntabilitas, good governance atau cooperative citizen. Sehingga

\footnotetext{
${ }^{52}$ Ibid

53 Pamadi Wibowo, Kaji Ulang Praktik CSR Perbankan, Artikel, Lingkar Studi CSR, jakarta, 28 Mei 2007, hlm 2.
} 
konsekuensi logisnya sebagai tulang punggung pendanaan berbagai proyek yang berdampak penting terhadap kemaslahatan sosial dan kelestarian lingkungan sudah sepantasnya menginternalisasikan dan mengimplementasikan konsep CSR dalam kiprah bisnisnya.

Pada Bank BCA belum adanya pelaksanaan CSR yang bersifat al-dloruriyah pada produk Bank tersebut. Yaitu belum adanya screening modal untuk suatu usaha yang tidak ramah sosial dan lingkungan. Hal ini terbukti dengan tidak adanya laporan yang menunnjukkan bahwa bank BCA memilih dan memilah proyek apa yang dibaiayai oleh Bank BCA. Berbeda pada Bank Muamalat Indonesia, terdapat beberapa pelaksanaan Screening proyek yang dibiayai adalah ramah lingkungan, hal ini dikeranakan pada Bank Muamalat terdapat peran pengawasan Syariah. Pengawas syaria ini berperan untuk menilai dan memberikan anjuran untuk berbagai pembiayaan yang tidak ramah sosial dan lingkungan.

Selanjutnya, pelaksanaan alDloruriyah terkait dengan pelaksanaan CSR Bank BCA dan Bank Muamalat adalah pada pelaksanaan CSR bersifat ikut mensejahterakan masyarakat dan menjaga lingkungan. Hal ini dianggap al-Dloruriyat karena menurut hemat penulis, bahwa kebanyakan bangsa Indonesia dibawah garis kemiskinan sehingga harus ada pemberdayaan ekonomi untuk masyarakat.

\section{PENUTUP}

Hasil penelitian menunjukkan bahwa Pelaksanaan Corporate Social Responsibility pada Bank BCA dan Bank Muamalat Indonesia terdapat kesamaan dan perbedaan. Kesamaannya terletak pada aspek pelaksanaan program tanggung jawab sosial (CSR), pada sektor pelaksanaan CSR Bank BCA dan Bank Muamalat yaitu berdasarkan Triple Bottom Line. Sedangkan perbedaan terletak pada prinsipprinsip yang mendasari pelaksanaan CSR, pada sisi pelaksana program, serta pada sumber dana CSR itu sendiri. Program Pelaksanaan CSR Bank BCA dan Bank Muamalat Indoensia jika dilihat dari tinjauan Ekonomi Islam. Pertama, jika dilihat dari sisi Islam Position in CSR Continuum, maka pelaksanaan CSR Bank BCA bersifat Strategic. Sedangkan pelaksanaan CSR pada Bank Muamalat bersifat TaqwaCentric. Perbedaan sumberdana CSR pada Bank Muamalat Indonesia dikarenakan Bank Muamalat Indonesia sebagai Bank Syariah pada prinsipnya mengemban fungsi sosial. Sehingga mereka dapat menghimpun dana ZISWAF, Wakaf dan dana sosial lainnya. 


\section{DAFTAR PUSTAKA}

Ali, Zainuddin. 2006. Hukum Islam: Pengantar IImu Hukum Islam di Indonesia Jakarta: Sinar

al-Bukhari, Abi

'Abdullah Muhammad ibn Ismail. 1403H. Al-Jami' al-Shahih li al-Bukhari, Juz ke-2. Qahira: al-Madba'ah asy-Syalafiyah.

al-Gazali, Abu Hamid Muhammad. 1417 H. al-Mustasfa min 'IIm al-Usul, tahqiq wa ta,liq Muhammad Sulaiman al-Asyqar, Juz ke-1. Beirut: Mu'assasat al-Risalah

al-Ifriqi, Jamal al-Din Muhammad ibn Mukarram ibn Manzur. 2003. Lisan al-'Arab, Juz ke-2, Riyad: Dar al-'Alam alKutub

Ambadar, Jackie. 2008, CSR dalam Praktik di Indonesia, Jakarta: Elex Media Komputindo

Amin, Wijaya Tunggal. 2007. Corporate Social Responsibility (CSR) Konsep dan Kasus, Jakarta: Harvindo, 2007.

Antonio, Muhammad Syafi'i. 2001, Bank Syariah Dari Teori ke Praktik, Jakarta:Gema Insani 2004, Bank Islam dari Teori ke Praktik, cet ke-8, Jakarta; Gema Insani.
Arikunto, Suharsimi. 1989, Prosedur Penelitian Suatu Pendekatan dan Praktik, (Jakarta: Bina Kasara).

Asy-Syātibi, 1984. al Muwafaqat fi Uhsul al-Ahkam, jilid 2, Kairo: Mustafa Muhammad.

Auda, Jasser. 2008. Maqhasid alSyariah as Philosophy of Islamic Law: a System Approach.Washington: The International Institute of Islamic Thought.

Bank BCA. 2012. Laporan Tahunan Bank BCA 2012. Jakarta: PT Bank Central Asia, 2012. . "Visi dan Misi Bank BCA". http://www.bca.co.id/id/abo ut/cari-tahu-tentangbca/visimisi/visimisilanding.jsp, diakses pada 20 Desember 2013, pukul 13:32 WIB.

"Bakti BCA". http://www.bca.co.id/id/abo ut/bakti-bca/bakti_bca.jsp, diakses pada 27 Desember 2013, pukul 12:53 WIB.

Bank Muammalat. 2012. Laporan Tahunan 2012, (jakarta: PT Bank Muamalat Indonesia Tbk, 2012. 
http://www.muamalatbank.c om/home/about/profile, diakses pada 20 Desember 2013, Pukul 13:49 WIB.

http://www.muamalatbank.c om/home/about/subsidary_b $\mathrm{mm}$ diakses pada 27 Desmeber 2013, pukul 11:15 WIB.

Beekum, Rafik Issa. 2004, Etika Bisnis Islami, Yogyakarta: Pustaka Pelajar

Bogdan, Robert., Tailor, Steven J. 1975, Introduction to Qualitative Research Methods, New York: John Wiley\& Sons.

Carrol, A. 1991. The Pyramid of Corporate Social Responsibility: Toward the Moral Managment of Organitazational Stakeholders, Jurnal, Business Horizons, JuliAgustus, 1991.

. 1999. Corporate Social Responsbility; Evolution of Definition Construct. Jurnal, Business and Society. Vol 38 (3)

Chapra, M. Umer. 2000. The Future of Economics: An Islamic
Perspective, Leicester: The Islamic Foundation.

Dashrud, Alexander. 2006. How Corporate Responsbility is Define: an Analysis of 37 Definitions. Wiley Inter Sciense, Jhon Wiley and Sons, Ltd and ERP Environment.

Departemen Hukum dan HAM. 2010. "Tanggung Jawab Sosial Perusahaan (Corporate social Responsibility) dan Iklim Penanaman Modal".

Djakfar, Muhammad. 2007. Etika Bisnia dalam Perspektif Islam, Malang: UIN Malang Press

Dusuki, Asyraf Wajdi. 2008, What Does Islam Say About Corporate Social Responsibility (CSR)?, Jurnal Review of Islamic Economics, Volume 12, Number 1, May 2008

Humayon, 2005, "Stakeholder's Perceptions Of Corporate Social Responsibility Of Islamic Banks: Evidence From Malaysian Economy", Jurnal, The $6^{\text {th }}$ International Conference on Islamic Economic and Finance, Vol.1 
Abdullah, Nurdianawati Irwani. 2007. Maqasid alShari`ah, Maslahah, and Corporate Social Responsibility. The American Jurnal of Islamic Social Siences. 24: 1.

Elkington, John. 2000. Cannibals With Forks: The Triple Bottom Line of 21st Century Business. Journal of Business Ethics. Volume 23, Number 2, January 2000.

Farouk, Sayd. 2007. On Corporate Social Responsbility of Islamic Financial Institutions. Islamic Economic Studies, Vol. 15. 2007.

Firdausi N, Nila. Corporate Social Responsbility: Sebuah Keniscayaan Strategi Bisnis di Indoensia, Artikel, Fakultas IImu Administrasi UNIBRAW.

Garriga, Elishabet., Mele, D. 2004. Corporate Social Responsibility Theories: Mapping The Territory, Journal of Business Ethics, Volume 53: 2004.

Hadi, Nor. 2011. Corporate Social Responsibility $(C S R)$, Yogyakarta: Graha Ilmu.
Hasaballah, Aliy. 1964, Usul alTasyri' al-Islamiy, Mesir: Dar al-Ma,,arif.

Hasyir, Dede Abdul. 2009. Praktek Corporate Social

Responsbility yang

Terintigrasi dan Contoh Implementasinya pada Industri Perbankan, Working Paper In Accounting and Finance, oktober 2009 Research Day, Faculty of Economics, Bandung: Padjadjaran University.

Hendrianto, MB., Astuti, Dwi Retno. 2008. Persepsi Stakeholder terhadap Pelaksanaan CSR (Kasus Pada Bank Syariah di DIY) Jurnal Sinergi Kajian Bisnis dan Manajemen. Vol 10 No. 1, Januari 2008

Hisan, Husain Hamid. 1971. Nazariyyat al-Maslahah fi al-Fiqh al-Islamiy, Beirut: Dar al-Nahdah al'Arabiyyah

Husein, Umar. 2009. Metode Penelitian untuk Skripsi dan Tesis. Jakarta: Rajawali Pers

ISO 26000 Guidance on Social Responsibility, draf 3, bagian 3.10. 2007

Jalal. 2008. CSR Perbankan di Indonesia: Antara Konsep dan Realitas. Artikel ini 
disampaikan pada temu Forum XVIII CFCD pada 31 maret 2008, Jakarta: Lingkar Studi CSR Indonesia.

Jalal al-Din, Abd al-Rahman. 1983. al-Masalih al-Mursalah wa Makanatuha fi al-Tasyri', t.tp: Matba, at al-Sa'adah,

Jauhar, Ahmad al-Mursi Husain. 2009. Maqashi Syariah, Jakarta: Sinar Grafika Offset.

Jensen, Michael C., Meckling, William H. 1976 Theory of the Firm: Managerial Behavior, Agency Costs and Ownership Structure, Journal of Financial Economics, October, 1976, V. 3, No. 4.

Jundiani, 2009, Pengaturan Hukum Perbankan Syariah di Indonesia, Malang: UIN Malang Press.

Kartini, Dwi. 2009. Corporate Social Responsibility: Transformasi Konsep Sustainability Management dan Implementasi di Indonesia, Jakarta: Refika Aditama.

Keraf, Sonny. 1998. Etika Bisnis Tuntutan dan Relevansinya. Yogyakarta: Kanisius.

Ki001, "Bank Muamalat 5 Kali Berturut-Turut Raih Penghargaan Bank Syariah
Terbaik"

http://www.kompasislam.co

m/2013/09/19/bank-

muamalat-5-kali-berturut-

turut-raih-penghargaan-

bank-syariah-

terbaik/,diakses pada 18

Desember 2013, Pukul 16: 48 WIB

Lingkar studi CSR Indonesia, 2007, Antara ISO 26000 dan Pasal 74 UU Perseroan Terbatas, CSR Indonesia Newsletter Vol. 1, Minggu, 2007.

Marnelly, T Romy, Corporate Social Responsbility (CSR): Tinjauan Teori dan Praktek di Indonesia, Jurnal Aplikasi Bisnis, Vol. 2 No. 2, April 2012.

Moleong, Lexy. 2002. Metodologi Penelitian Kualitatif.

Bandung: PT. Remaja Rosdakarya.

Meutia, Inten. 2010. Menata Pengungkapan CSR di Bank Islam (Suatu Pendekatan Kritis), Jakarta: Citra Pustaka Indonesia.

Muhammad. 2002. Manajemen Bank Syariah, Yogyakarta : UUP AMP YKPN

Fauroni, Lukman. 2002. Visi Al-Quran tentang 
Etika dan Bisnis, Jakarta: Salemba Diniyah.

Muwazir, M. Rizal. Corporate Social Responsibility In The Context Of Financial Services Sector In Malaysia, Desertasi, Cardiff University.

Naqvi, Syed Nawab Haidar. 2003. Menggagas Ekonomi Islam. Yogyakarta: Pustaka Pelajar.

Nor, Shifa Mohd., Asutay, Mehmet. Re-Considering CSR and Sustainability Identity of Islamic Banks in Malaysia: An Empirical Analysis, Makalah, Disampaiakan pada 8th International Conference on Islamic Economics and Finance, diselenggarakan oleh Qatar Fundation, 19-21 Desember 2011.

Peraturan Pemerintah No 47 Tahun 2012 tentang Tanggung Jawab Sosial dan Lingkungan Perseroan Terbatas.

Phillips, Robert., dkk. 2003. What Stakeholder Theory Is Not, Journal Business Ethic Quarterly, volume 13, issu 44, 2003.

Qardhawi, Yusuf. 1997. Peran Nilai dan Moral dalam Perekonomian Islam, Penerjemah didin hafiduddin.dkk. Jakarta: Robbani Press.

Rivai, Veitrihal., Buchari, Andi. 2009. Islamic Economics: Ekonomi Syariah Bukan Opsi Tapi Solusi!, Jakarta: Bumi Aksara.

Saidi, Zaim. Membangun CSR dan Filantropi yang Aplikatif, Artikel. hlm, 3-4. http://www.ibl.or.id/en/ibl/ht $\mathrm{ml}$ /data/File/PPF/filan_perus/ Membangun_CSR_dan_Filant ropi_yang_Aplikatif.pdf. akses pada 18 November 2013 jam 13:20.

Saleh, Mohammad. 1998 Pengantar Syariat Islam, Kuala Lumpur: Pustaka Haji Abdul Majid.

Sembiring, Edi Rismanda. 2003. Faktor-Faktor yang Mempengaruhi Pengungkapan Tanggung Jawab Sosial Perusahaan. Jurnal Telaah Akuntansi, Volume: 01 No. 01 Juni 2003.

Sjahdeini, Sutan Remy. 2007. Perbankan Islam, cet ke-3. Jakarta: PT Pustaka Utama Grafiti. 
Siagian, Matias., Suriadi, Agus. 2010, CSR Perspektif Pekerjaan Sosial, Medan: FISIP USU Press.

Sofyan, Hafiz., dkk, 2012, Islamic Social Reporting Index Sebagai Model Pengukuran Kinerja Sosial Perbankan Syariah (Studi Komparasi Indonesia Dan Malaysia), Jurnal dinamika Akuntansi, Vol. 4. No. 1, Maret 2012.

Supardi. 2005. Metodologi Penelitian Ekonomi Bisnis. Yogyakarta: UII Press.

Syarifuddin, Amir. 2001. Ushul Fiqh 2, Jakarta: Logos Wacana IImu.

Tregidga, Helen., dkk. 2007. Organisational Legitimacy And Social And Environmental reporting Research: The Potential of Discourse Analysis, this paper were presented at the 5th Australasian Conference on Social and Environmental Accounting Research, Wellington, 2006 and the 5th Asia-Pacific Interdisciplinary Research in Accounting (APIRA) Conference, Auckland, 2007. Aucklan: Auckland University Of Technology.
Undang-Undang No. 7 Tahun 1992.

Undang-Undang Nomor 10 tahun 1998.

Undang-Undang Nomor 25 Tahun 2007 tentang Penanaman Modal.

Undang-Undang Nomor 40 tahun 2007 tentang Perseroan terbatas.

Undang-Undang Nomor 21 tahun 2008 tentang perbankan syariah

Wahyudi, Isa., Azheri, Busyra. 2008, Corporate Social Responsibility: Prinsip, Pengaturan dan Implementasi, Malang: InTrans Publishing.

WBP. "Ini Daftar Bank Terbaik Versi Majalah Investor" http:// www.beritasatu.com/bankdan-pembiayaan/117757-inidaftar-bank-terbaik-versimajalah-investor.html, diakses pada 18 Desember 2013, pukul 16:30 WIB.

Wibawa, Annisa Aninditya. "Lima bank syariah dengan laba terbesar" http://keuangan .kontan.co.id/news/limabank-syariah-dengan-labaterbesar, diakses pada 18 desember 2013, pukul 17:00 WIB 
Wibisono, Yusuf. 2007. Membedah Konsep dan Aplikasi Corporate Social

Responsibility, Jakarta : Salemba Empat.

Wibowo, Pamadi. 2007. Kaji Ulang Praktik CSR Perbankan, Artikel, Lingkar Studi CSR, jakarta, 28 Mei 2007.

Wiroso. 2009. Produk Perbankan Syariah, edisi 1 , cetakan 1. Jakarta: LPFE Usakti

Yupitri, Evi., Sari, Raina Linda. 1992, Analisis Faktor-Faktor Yang Mempengaruhi Non Muslim Menjadi Nasabah Bank Syariah Mandiri Di Medan, Jurnal Ekonomi dan Keuangan, Vol.1. No, 1, Desember 2012.

Yusuf, Muhammad Yasir. 2010, "Model Pelaksanaan CSR Bank Syariah: Kajian Empiris Pembiayaan Mikro Baitul Mal Aceh", Jurnal La-riba Volume IV. No. 2 Desember. , 2010. "Aplikasi CSR Pada Perbankan Syariah : Suatu Pendekatan Maslahah dan Maqashid Syari'ah". Jurnal Ekonomi dan Bisnis Islam Vol.4, No. 2, Juni 2010. dan Bahari, Zakaria Bin. Islamic Corporate Social Responsbility in Islamic
Banking: Towards Poverty Alleviation, Makalah di seminarkan pada $8^{\text {th }}$ International Conference on Islamic Economics and finance, Center for Islamic and Finance, Qatar Faculty of Islamic Studies, Qatar Fondation, 19-21 Desember 2011.

Zuhaili, Wahbah. 1986. Adillatul alFiqh al-Islami, juz II. Beirut: Dar al-fikri 